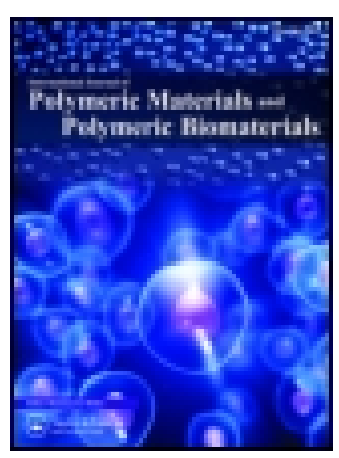

International Journal of Polymeric Materials and Polymeric Biomaterials

ISSN: 0091-4037 (Print) 1563-535X (Online) Journal homepage: http://www.tandfonline.com/loi/gpom20

\title{
Thermosensitive Hydrogels for Modified Release of Ellagic Acid Obtained From Alchemilla Vulgaris L. Extract
}

Snežana Ilić-Stojanović , Vesna Nikolić, Tatjana Kundaković, Ivan Savić, Ivana Savić-Gajić, Emilija Jocić \& Ljubiša Nikolić

To cite this article: Snežana llić-Stojanović , Vesna Nikolić, Tatjana Kundaković, Ivan Savić, Ivana Savić-Gajić, Emilija Jocić \& Ljubiša Nikolić (2017): Thermosensitive Hydrogels for Modified Release of Ellagic Acid Obtained From Alchemilla Vulgaris L. Extract, International Journal of Polymeric Materials and Polymeric Biomaterials, DOI: 10.1080/00914037.2017.1354202

To link to this article: http://dx.doi.org/10.1080/00914037.2017.1354202

Accepted author version posted online: 24 Jul 2017.

Submit your article to this journal $₫$

山 Article views: 11

Q View related articles $\longleftarrow$

View Crossmark data 
Check for updates

\title{
Thermosensitive Hydrogels for Modified Release of Ellagic Acid Obtained from Alchemilla vulgaris L. Extract
}

Snežana Ilić-Stojanović ${ }^{1, *}$, Vesna Nikolić ${ }^{1}$, Tatjana Kundaković ${ }^{2}$, Ivan Savić ${ }^{1}$, Ivana Savić-Gajić ${ }^{1}$, Emilija Jocić ${ }^{1}$, Ljubiša Nikolić ${ }^{1}$

${ }^{1}$ University of Niš, Faculty of Technology, Leskovac, Republic of Serbia ${ }^{2}$ University of Belgrade, Faculty of Pharmacy, Belgrade, Republic of Serbia

Correspondence PhD Snežana Ilić-Stojanović, University of Niš, Faculty of Technology, Bulevar oslobodjenja 124, 16000 Leskovac, Republic of Serbia E-mail:

ilic.s.snezana@gmail.com

\begin{abstract}
Stimuli-sensitive hydrogels are used as carriers for modified release of pharmaceuticals. The synthesis of thermo-sensitive hydrogels poly( $N$-isopropylacrylamide), p(NIPAM), and poly( $N$-isopropylacrylamide-co-2-hydroxypropyl methacrylate), p(NIPAM-HPMet), is performed. The synthesized hydrogels are characterized using FTIR and SEM methods and swelling properties and applied for modified release of ellagic acid (EA). This work presents selective extraction of EA, as natural antioxidant, from the aerial parts of Alchemilla vulgaris L. EA and A. vulgaris extract are incorporated into p(NIPAM) and p(NIPAM-HPMet) hydrogels and characterized by FTIR method. The EA content in the extract by the UHPILC-DAD-HESI-MS/MS method is determined $\left(0.64 \mathrm{mgcm}^{-3}\right)$. The total flavonoids content in the A. vulgaris extract was determined by the spectrophotometric method. Antioxidant activity of the A. vulgaris extract and EA is examined using the DPPH assay. The p(NIPAM-HPMet) shows a better incorporation and release at $37^{\circ} \mathrm{C}$ of EA standard and A. vulgaris extract (98.87 and $96.45 \%$ respectively), compared with a $\mathrm{p}(\mathrm{NIPAM})$.
\end{abstract}




\section{Graphical Abstract}<smiles>O=c1oc2c(O)c(O)cc3c(=O)oc4c(O)c(O)cc1c4c23</smiles>

Ellagic acid

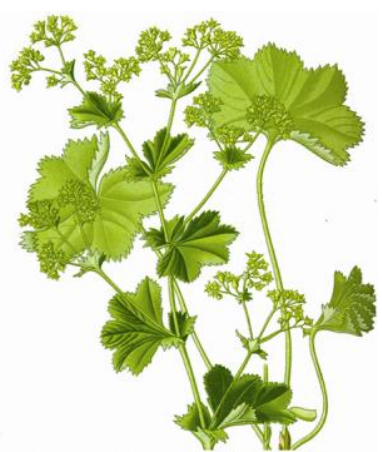

Alchemilla vulgaris L.

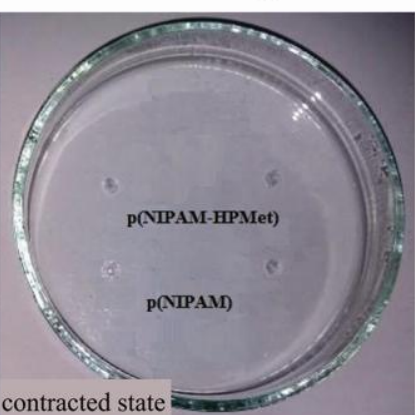

KEYWORDS: Hydrogels, $N$-isopropylacrylamide, thermosensitive release, ellagic acid, Alchemilla vulgaris L.

\section{INTRODUCTION}

The hydrogels belong to polymeric materials, which have the ability to absorb large quantities of water or physiological fluids, retaining their structure. Hydrogels properties (swelling degree, mechanical properties, etc.) can be controlled by selecting the monomers and synthesis conditions. Thus, the resulting hydrogels respond to a various external stimuli (temperature and $\mathrm{pH}$ value) by changing any of specified characteristics (e.g. degree of swelling) and that was the reason why they got the name "intelligent gels". 
Hydrogels resemble the living tissues due to the high water content, elastic and soft consistency [1]. Because of the favorable properties, they have variety of applications in medicine and pharmacy, mainly thermosensitive poly( $N$-isopropylacrylamide), p(NIPAM). The hydrogels capacity to absorb and release different sizes of molecules was applied in drug carrier systems for modified release of pharmaceutically active substances [2,3]. Most frequently, the component in the hydrogel synthesis is thermosensitive $N$-isopropylacrylamide (NIPAM) which copolymerizes with a specific amount of an anionic monomer (acrylic, methacrylic, maleic or itaconic acid) in order to obtain hydrogels sensitive to changes in temperature and $\mathrm{pH}$ [4-6]. The lower critical solution temperature (LCST) of copolymers containing NIPAM with acid component is shifted to the higher temperatures, as compared to the LCST of p(NIPAM). By designing the copolymer composition, LCST can be moved closely to the physiological body temperature, which was especially important for modified release of drugs [7-9]. These results were a part of wider investigation of hydrogels [10] as drug carriers [11,12].

Ellagic acid, (EA) 4,4',5,5',6,6'-hexahydroxydiphenic acid-2,6,2',6'-dilactone, $\mathrm{C}_{14} \mathrm{H}_{6} \mathrm{O}_{8}$, represents a dilactone of hexahydroxydiphenic acid, with molar mass of $302.197 \mathrm{~g} \mathrm{~mol}^{-1}$. EA was discovered by the chemist Braconnot in 1831 [13]. This is a natural phenolic antioxidant that can be found in many plant species. EA shows antioxidant properties in vitro and in vivo [14-16]. Antiproliferative properties of EA can be attributed to possibility to directly inhibit the binding of certain carcinogens to DNA $[17,18]$. EA has a chemopreventive effect in cellular models by reducing oxidative stress. It shows antimutagenic and antiinflammatory activity $[19,20]$. EA is effective in the treatment of 
various tumors, eg. tumors of pancreas, lung, or colon [21-23]. Soh and colleague found the effectivness of EA against malaria parasites and in vitro potentiation of the effect of antimalarial drugs [24].

In this study, Alchemilla vulgaris L. was selected as a plant material for the isolation of EA, as important anticancer agens. This is a herbaceous plant of the rose family (Rosaceae). Traditionally, it is used to treat ulcers, eczema and skin rashes, because of established anti-inflammatory properties. It helps in solving some symptoms, caused by menopausal and adolescent conditions. As the drug, above-ground part of the plant in bloom was used (Alchemillae herba), less frequently leaves, which have a low bitter and astringent taste. It was known that the plant contains: tannins, gallic acid, ellagic acid, bitter glycosides, saponins, flavonoids (quercetin and luteolin and their glycosides), and a bit essential oil [25-28]. Also, it contains polyphenols which contributed to the main pharmacological activity of the plant [26]. Its active ingredients acts on the blood vessels, inhibiting degradation of the intracellular matrix by proteases [27,29] and they are important anti-oxidants [30]. Flavonoids are the subject of numerous studies especially for biological and pharmacological effects, especially in malignant diseases [31].

The aim of this study was extraction of the A. vulgaris aerial parts and their characterisation. Also, the total flavonoids content in A. vulgaris extract, as well as the antioxidant activities of the extract and EA were defined. Homopolymer p(NIPAM) and copolymer poly( $N$-isopropylacrylamide-co-2-hydroxypropyl methacrylate), p(NIPAMHPMet), were synthesized and characterized. Because EA is highly insoluble molecule, 
obtained hydrogels were applied as carriers for their modified release in purpose of better solubility and distribution.

\section{EXPERIMENTAL}

\subsection{Reagents}

$\mathrm{N}$-isopropylacrylamide, 2,2'-azobis(2-methylpropionitrile) and 2-

hydroxypropilmethacrylate were purchased from Acros Organics (USA). Ethyleneglycole dimethacrylate was purchased from Fluka (Switzerland). Cyclohexane, 99.5\% aluminium chloride, potassium acetate, 2,2-diphenyl-1-picrylhydrazyl, ellagic acid, 95\%, methanol 70\% and 99.9\% HPLC grade were purchased from Chromasolv (Germany). Potassium bromide, $\mathrm{KBr}, 99 \%$ (IR grade), dichloromethane and rutin 95\%, was purchased from Merck (Germany). Aceton, AC, 99.5\%, ethanol, 96\% and BHT were purchased from Centrohem (Serbia). Acetonitrile and water (LC-MS and HPLC grade) were supplied from Fisher Chemical (Germany). Formic acid was purchased from Carlo Erba (France).

\subsection{Plant Material}

Alchemilla vulgaris L. was purchased from Adonis (Serbia), stored on the dried and cold place without direct exposed to the sunlight, then, grinded to small sizes in a laboratory mill.

\subsection{Synthesis Of Hydrogels}

By the radical polymerization of monomers NIPAM and 20 mol\% of HPMet with 0.5 mol\% of crosslinker EGDM, a copolymer p(NIPAM-HPMet) was synthesized. AC was 
used as a suitable solvent. The p(NIPAM) was synthesized by radical polymerization of NIPAM with 0.5 and 2 mol\% EGDM. Both reactions were initiated by 2,2'-azobis(2methylpropionitrile). The polymerization was thermally initiated according to following regime: $30 \mathrm{~min}$ at $70^{\circ} \mathrm{C}, 120 \mathrm{~min}$ at $80^{\circ} \mathrm{C}$ and $30 \mathrm{~min}$ at $85^{\circ} \mathrm{C}$. After cooling, obtained $\mathrm{p}$ (NIPAM) and p(NIPAM-HPMet) hydrogels were separated from the glass tubes and cut into small discs. The hydrogels $(0.5 \mathrm{~g})$ were treated with methanol $\left(30 \mathrm{~cm}^{3}\right)$ for $72 \mathrm{~h} \mathrm{in}$ order to remove all compounds which did not react. After that, hydrogels were immersed in a solutions of methanol/distilled water 75/25, 50/50, 25/75 and $0 / 100 \%(\mathrm{v} / \mathrm{v})$, per $24 \mathrm{~h}$, in order to gradual elution of methanol from hydrogels and then dried for $2 \mathrm{~h}$ at $40^{\circ} \mathrm{C}$. In order to protect the hydrogel structures, the samples were dried in a desiccator at $25^{\circ} \mathrm{C}$ to a constant mass.

\subsection{Extraction Of EA From A. Vulgaris}

The aerial parts of commercial sample of A. vulgaris (245 g) were extracted with cyclohexane two times at the solid to liquid ratio of 1:5 (m/v) and room temperature for $48 \mathrm{~h}$. After the extraction, the liquid was separated from a solid matrix by filtration with Büchner funnel. The same extraction procedure was repeated using dichloromethane and $70 \%(\mathrm{v} / \mathrm{v})$ methanol. The obtained extracts were evaporated under vacuum by rotary evaporator. After the evaporation of solvents, the yield of methanol extract was $24.93 \mathrm{~g}$.

The extract were dried and stored in a desiccator before analysis.

\subsection{Characterization}

2.5.1 Infrared Spectroscopy With Fourier Transformation (FTIR) 
The FTIR spectra of reactants, synthesized xerogels p(NIPAM) and p(NIPAM-HPMet), EA standard, A. vulgaris extract with EA content, xerogels of p(NIPAM) and p(NIPAMHPMet) with incorporated EA and A. vulgaris extract, were recorded using the $\mathrm{KBr}$ method. The transparent tablets were prepared by compression of samples $(0.7 \mathrm{mg})$ and $\mathrm{KBr}(150 \mathrm{mg})$ under a pressure of $200 \mathrm{MPa}$. Recordings were performed on FTIR spectrophotometer Bomem MB-100 (Hartmann \& Braun, Canada) in the wavenumber range of 4000-400 $\mathrm{cm}^{-1}$. The interpretation of FTIR spectra was carried out using the software Win-Bomem Easy.

\subsubsection{Scanning Electron Microscopy (SEM)}

Scanning electron microscopy (SEM) was used to examine the morphology of the synthesized xerogels, pure and with loaded EA. Before cutting, samples were submerged in liquid nitrogen in order to avoid deformation and breakage. The conductive layers, gold/palladium alloy (15/85) were coated on surface samples by using a JEOL JFC$1100 \mathrm{E}$ Ion Sputter to prevent the electronic charge formation. Scans were performed on the JEOL Scanning Microscope JSM-5300 (JEOL Co., Japan).

\subsubsection{Equilibrium Hydrogel Swelling}

The xerogel samples were immersed in a solution with a $\mathrm{pH}=7.40$ at $37^{\circ} \mathrm{C}$. Swelling process was monitored gravimetrically by measuring the mass of samples at specific time intervals. The swelling degree, $\alpha_{\mathrm{t}}$ was calculated according to equation (1):

$$
\alpha_{t}=\frac{m_{t}-m_{0}}{m_{0}}
$$

wherein: $m_{0}$ xerogels mass, $m_{\mathrm{t}}$ mass of the swollen hydrogel at time interval $t$. 


\subsubsection{Thermosensitivity Hydrogels Testing}

The process of the hydrogel contraction and the phase transition was accompanied by the loss of water through the hydrogel depending on the time at temperatures $10-50^{\circ} \mathrm{C}$.

\subsubsection{UHPLC-DAD-HESI-MS/MS Analysis}

UHPLC-DAD-HESI-MS/MS analysis was performed by Thermo Scientific liquid chromatography system (UHPLC) composed of a quaternary pump with a degasser, a thermostated column compartment, an autosampler, and a diode array detector connected to LCQ Fleet Ion Trap Mass Spectrometer (Thermo Fisher Scientific, USA) equipped with heated electrospray illipore (HESI). Xcalibur (version 2.2 SP1.48) and LCQ Fleet (version 2.7.0.1103 SP1) software were used for instrument control, data acquisition and analysis. Separations were performed on Hypersil gold C18 column $(50 \times 2.1 \mathrm{~mm}, 1.9$ $\mu \mathrm{m})$ obtained from Thermo Fisher Scientific. The mobile phase consisted of (A) water+0.1\% formic acid and (B) acetonitrile. A linear gradient program at flow rate of $0.350 \mathrm{~cm}^{3} \mathrm{~min}^{-1}$ was used $0-2 \mathrm{~min}$ from 10 to $20 \%$ (B), 2-4.5 min from 20 to $90 \%$ (B), 4.5-4.8 $\min 90 \%$ (B), 4.8-4.9 min from 90 to $10 \%$ (B), 4.9-12.0 min $10 \%$ (B). The injection volume was $5 \mu \mathrm{L}$ and temperature column of $25^{\circ} \mathrm{C}$. Spectral data from all peaks were recorded at 256 and $367 \mathrm{~nm}$. The mass spectrometer was operated in negative mode. HESI-source parameters were as follows: source voltage $4.5 \mathrm{kV}$, capillary voltage -31.00 $\mathrm{V}$, tube lens voltage $-110.40 \mathrm{~V}$, capillary temperature $300^{\circ} \mathrm{C}$, sheath and auxiliary gas flow $\left(\mathrm{N}_{2}\right) 32$ and 12 (arbitrary units). MS spectra were acquired by full range acquisition covering 150-700 m/z. For fragmentation study, a data dependant scan was performed by 
deploying the collision-induced dissociation (CID). The normalized collision energy of the collision-induced dissociation (CID) cell was set at $25 \mathrm{eV}$.

\section{Preparation Of Samples For MS Analysis}

Basic solutions of EA standard and A. vulgaris extract were made by dissolving $10 \mathrm{mg}$ of sample in $10 \mathrm{~cm}^{3}$ of methanol. Subsequently, the basic solutions $\left(1 \mathrm{mgcm}^{-3}\right)$ were diluted to a concentration of $5 \mathrm{gcm}^{-3}$ and injected to a MS spectrometer.

\subsubsection{DPPH Assay}

The ability of the compound to scavenge free DPPH radicals was determined by socalled, DPPH assay [32-34]. The series of different concentrations were prepared from the stock solution of EA standard $\left(0.1 \mathrm{mgcm}^{-3}\right), A$. vulgaris extract $\left(1.0 \mathrm{mgcm}^{-3}\right)$ and BHT $\left(0.5 \mathrm{mgcm}^{-3}\right) .1 \mathrm{~cm}^{3}$ of the ethanolic solution of DPPH radical $\left(3 \cdot 10^{-4}\right.$ moldm$\left.^{-3}\right)$ was added in all samples of different concentrations of EA and extract $\left(2.5 \mathrm{~cm}^{3}\right)$. The absorbance of the ethanolic solution of DPPH radical obtained by dilution of DPPH radical stock solution $\left(1 \mathrm{~cm}^{3}\right)$ with addition of $2.5 \mathrm{~cm}^{3}$ ethanol was measured under the same conditions. Samples were incubated in dark at room temperature for $30 \mathrm{~min}$. The absorbance of samples were measured compared with $96 \%(\mathrm{v} / \mathrm{v})$ ethanol at $517 \mathrm{~nm}$ and room temperature using Varian Cary-100 Conc. Instrument. The quartz cuvettes $(1 \times 1$ $\mathrm{cm}$ ) were used for scanning. The inhibition of DPPH radicals was calculated using the equation (2):

inhibition of DPPH radicals $(\%)=100 \cdot\left(1-\frac{A s-A_{B}}{A_{C}}\right)$ 
where $A_{\mathrm{S}}$ is absorbance of samples (samples ethanolic solution with addition of DPPH radicals), $A_{\mathrm{B}}$ is absorbance of blank (samples ethanolic solution without DPPH radicals), $A_{\mathrm{C}}$ is absorbance of the control solution (the diluted ethanolic solution of DPPH radicals, $\left.3 \cdot 10^{-4} \mathrm{moldm}^{-3}\right)[35,36]$.

\subsubsection{Determination Of Total Flavonoids}

The spectrophotometric method with aluminum chloride was used for determination of total flavonoid content in A. vulgaris extract. This method presents the modified procedure of Woisky and Salatino $[37,38]$. The total flavonoids content was expressed as rutin equivalents. The stock solution of rutin was prepared by dilution of rutin standard (10 mg) in 96\% (v/v) ethanol. The series of different rutin concentrations was prepared from the stock solution. $1.5 \mathrm{~cm}^{3}$ of $96 \%$ (v/v) ethanol, $0.1 \mathrm{~cm}^{3}$ of aluminium chloride $(10 \%)$ and $0.1 \mathrm{~cm}^{3}$ of potassium acetate $\left(1 \mathrm{moldm}^{-3}\right)$ and $2.8 \mathrm{~cm}^{3}$ of distilled water were added into each of the solutions $\left(0.5 \mathrm{~cm}^{3}\right)$. After incubation at room temperature of 30 min, the absorbance was measured at $415 \mathrm{~nm}$. Instead the aluminium chloride, the equivalent amount of distilled water was added in the blank solution.

The series of different $A$. vulgaris extract concentrations were prepared by dilution of the stock solution of $1 \mathrm{mgcm}^{-3}$. In order to form aluminum chloride complex with flavonoids, per $0.5 \mathrm{~cm}^{3}$ of the prepared A. vulgaris extract solutions was taken and then samples were treated by the same procedure as rutin during the calibration curve construction.

\subsubsection{Incorporation Of EA And A. Vulgaris Extract In The Hydrogels}


Solutions of the EA standard and the A. vulgaris extract, $1 \mathrm{mg} \mathrm{cm}^{-3}$ in the methanol (99.9\%), were prepared for their incorporation in synthesized p(NIPAM) and p(NIPAMHPMet). Then, xerogel samples of $\mathrm{p}(\mathrm{NIPAM})$ and $\mathrm{p}(\mathrm{NIPAM}-\mathrm{HPMet})$ were weighed (per $0.050 \mathrm{~g}$ ) and perfused by $1.5 \mathrm{~cm}^{3}$ of prepared solutions and left to swell for $48 \mathrm{~h}$. Available quantity of EA for incorporation into the hydrogel was $30 \mathrm{mgg}_{\text {xerogel }}{ }^{-1}$. After reaching the equilibrium swelling state of hydrogels, the excess solutions were separated by decanting. Hydrogels were washed with distilled water to remove the excess amount of EA or A. vulgaris extract from the surface. In order to calculate the efficiency of EA incorporation, the mass of all samples were weighted. The EA release from hydrogels under conditions which simulating the intestinal fluid was examined in vitro.

\subsubsection{The EA Release From The Hydrogels}

Standard solutions of EA in methanol in the range $0.001-0.1 \mathrm{mg} \mathrm{cm}^{-3}$ were prepared. Based on the dependency of peaks area and the known EA concentrations, a calibration curve was constructed. The released EA amounts were calculated using the equation for the calibration curve. Samples of swollen hydrogel with incorporated EA were topped with $5 \mathrm{~cm}^{3}$ of aqueous solution of $\mathrm{pH}=7.40$ and then thermostated at $37^{\circ} \mathrm{C}$ with vigorous magnetic stirring for $24 \mathrm{~h}$. The released amount of EA was monitored using UHPLC-

DAD-HESI-MS/MS method in time intervals ( $0,0.5,1,1.5,2,4$ and $24 \mathrm{~h})$. The injected volume of samples was $20 \mu 1$. The solutions were diluted with acetonitrile up to $2 \mathrm{~cm}^{3}$ and then filtered through a $0.45 \mu \mathrm{m}$ millipore filter (Econofilters, Agilent Technologies, Germany) before injecting the samples into the system. 


\section{RESULTS AND DISCUSSION}

In this study, the p(NIPAM-HPMet) hydrogel with $0.5 \mathrm{~mol} \%$ of EGDM was chosen from a series of synthetized hydrogels for incorporation of EA and A. vulgaris extract due to the best swelling properties at $37^{\circ} \mathrm{C}$ and $\mathrm{pH} 7.40$ [11]. The $\mathrm{p}(\mathrm{NIPAM})$ hydrogel with 0.5 mol\% of EGDM was omitted from further investigation because of liquid consistency.

\subsection{FTIR Analysis}

In the FTIR spectrum of the NIPAM (Figure 1), a high intensity band at $3284 \mathrm{~cm}^{-1}$ originating from the $v(\mathrm{NH})$ was present. The band at $3072 \mathrm{~cm}^{-1}$ corresponding to $v_{\text {as }}(=\mathrm{CH})$ of the vinyl groups. Amide I band appears at $1658 \mathrm{~cm}^{-1}$, indicating the secondary amide was associated. Amide II band originates from $\delta(\mathrm{NH})$ that is coupled with $v(\mathrm{CN})$ vibrations and gives the band at $1556 \mathrm{~cm}^{-1}$, which was derived from transform of acyclic secondary amides. Another indication that a trans-form of the secondary acyclic amide gives band at $1306 \mathrm{~cm}^{-1}$ was attributable to amide III band, of $v(\mathrm{CN})$ coupled to $\delta(\mathrm{NH})$ from the amide group, appeared at $1300 \mathrm{~cm}^{-1}$. A terminal double-bond, $v(\mathrm{C}=\mathrm{C})$, gives the band at $1622 \mathrm{~cm}^{-1}$. The confirmations of monosubstituted doublebonds existence were two high intensity bands of $\gamma(\mathrm{CH})$ at 992 and $964 \mathrm{~cm}^{-1}$, which is in accordance with literature [39]. The presence of $v(\mathrm{C}=\mathrm{C})$ and $\gamma(\mathrm{CH})$ bands in NIPAM spectrum are important for polymerization process monitoring.

In the FTIR spectrum of the synthesized p(NIPAM) the bands from $v(\mathrm{C}=\mathrm{C})$ at 1622 $\mathrm{cm}^{-1}$ and $\gamma(=\mathrm{CH})$ at 992 and $964 \mathrm{~cm}^{-1}$ are not present (Figure 1). This indicates that the polymerization of NIPAM was made through a double-bond of vinyl groups forming a 
main chain and the residues from NIPAM monomers present the homopolymer side chains. In regard to the amide groups present in $\mathrm{p}(\mathrm{NIPAM})$ side chains, the formation of hydrogen bonds between the $\mathrm{C}=\mathrm{O}$ and $\mathrm{NH}$ groups of the adjacent side chain is possible. The hydrogen bonds formation between the above mentioned side-chain of $\mathrm{p}$ (NIPAM) were indicated by the $v(\mathrm{NH})$ and $v(\mathrm{C}=\mathrm{O})$ bands shifting in the $\mathrm{p}(\mathrm{NIPAM})$ spectrum, in comparison to the same bands in the NIPAM monomer spectrum. In p(NIPAM) spectrum, $v(\mathrm{NH})$ band was shifted by 5 unit to the higher wavenumbers and appears at $3289 \mathrm{~cm}^{-1}$, amide I band, $v(\mathrm{C}=\mathrm{O})$, which occurs at $1648 \mathrm{~cm}^{-1}$, was shifted by 10 units to lower wavenumbers, compared to same bands in NIPAM spectrum, which is consistant with literature [40].

FTIR spectrum of synthesized p(NIPAM-HPMet) (Figure 1) also, has no absorption band of $v(C=C)$ in the area $1620-1640 \mathrm{~cm}^{-1}$, confirming that polymerization was achieved via double-bond from vinyl groups of monomers. A broad band with two clearly separated saddle, at $3319 \mathrm{~cm}^{-1}$ and $3438 \mathrm{~cm}^{-1}$, originate from $v(\mathrm{NH})$ of NIPAM and $v(\mathrm{OH})$ from 2-hydroxypropilmethacrylate (HPMet). There has been a shift of $v(\mathrm{NH})$ band for 16 units to the higher wavenumbers, compared to their position in the NIPAM spectrum. Also, $\delta(\mathrm{OH})$ band at $1460 \mathrm{~cm}^{-1}$ was shifted for 5 units to higher wavenumbers compared to the FTIR spectrum of HPMet. This shift and the presence of a wide band in the area around $3400 \mathrm{~cm}^{-1}$ indicate the formation of hydrogen bonds between the side chains of the copolymer via $\mathrm{OH}$ and $\mathrm{NH}$ groups, which was consistent with literature data [41]. The amide $\mathrm{I}$ band $v(\mathrm{C}=\mathrm{O})$ was present at $1650 \mathrm{~cm}^{-1}$ in the copolymer spectrum. Its shifting to 8 units to lower wavenumbers in the copolymer, compared to the same band in 
NIPAM spectrum, indicates that $\mathrm{C}=\mathrm{O}$ groups participated in formation of hydrogen bonds. In $\mathrm{p}(\mathrm{NIPAM}$-HPMet) spectrum there was $v(\mathrm{C}=\mathrm{O})$ band of the ester group at 1728 $\mathrm{cm}^{-1}$, a band of $\delta(\mathrm{NH})$ at $1544 \mathrm{~cm}^{-1}$, as well as a band of $v_{\mathrm{s}}(\mathrm{CO})$ at $1173 \mathrm{~cm}^{-1}$.

In the EA standard FTIR spectrum (Figure 1) a sharp medium intensity band at $3557 \mathrm{~cm}^{-1}$ was attributed to the valence vibrations of phenolic hydroxyl groups, $v(\mathrm{Ar}-\mathrm{OH})$, which was in accordance with literature [42]. Also, bands of $\delta(\mathrm{OH})$ and $\gamma(\mathrm{OH})$ were present in the EA spectrum at 1448 and $923 \mathrm{~cm}^{-1}$, respectively. The complex absorption band in the area $3500-2750 \mathrm{~cm}^{-1}$ with peaks at $2929,2813,2326 \mathrm{~cm}^{-1}$ was attributable to $v(\mathrm{CH})$ from an aromatic part of the structure [43]. Bands at $3140 \mathrm{~cm}^{-1}$ and $3093 \mathrm{~cm}^{-1}$ could be attributed to the valence vibration of intramolecular hydrogen bond in the EA molecule [44]. The band at $1701 \mathrm{~cm}^{-1}$ was attributed to $v_{\mathrm{s}}(\mathrm{C}=\mathrm{O})[45,46]$ and bands at 1621,1583 and $1509 \mathrm{~cm}^{-1}$ originate from $v(\mathrm{C}=\mathrm{C})$ Ar. Bands at 1195 and $1057 \mathrm{~cm}^{-1}$ derived from $v(\mathrm{CO})$ from the ester part of structure dilactone [47]. The band at $760 \mathrm{~cm}^{-1}$ was the consequence of $\gamma(\mathrm{Ar}-\mathrm{C}-\mathrm{H})$.

FTIR spectrum of A. vulgaris extract (Figure 1) was different from the EA standard FTIR spectrum, as expected, because in the extract there are some other compounds, especially from the phenolics, besides the EA. In FTIR spectrum of the extract, the bands occurring at 3431,1448 and $919 \mathrm{~cm}^{-1}$ of $v(\mathrm{Ar}-\mathrm{OH}), \delta(\mathrm{OH})$ and $\gamma(\mathrm{OH})$, respectively, confirm EA presence in the extract. Confirmation of aromatic parts in the structure were bands at $2929 \mathrm{~cm}^{-1}$ of $v(\mathrm{CH})$, at 1355 and $1230 \mathrm{~cm}^{-1}$ of the $\delta(\mathrm{Ar}-\mathrm{CH})$ and the wider, complex, weaker intensity $\gamma(\mathrm{Ar}-\mathrm{CH})$ band at $751 \mathrm{~cm}^{-1}$. The band at $1728 \mathrm{~cm}^{-1}$ was attributed to 
$v_{\mathrm{s}}(\mathrm{C}=\mathrm{O})$ from the keto group of the lactone structure, which were present as a part of EA structure in the extract, whereas $v(\mathrm{CO})$ in this part of the structure giving the bands at 1193 and $1048 \mathrm{~cm}^{-1}$. Also, there are $v(\mathrm{C}=\mathrm{C})$ bands from the aromatic ring were present in the extract spectrum at 1618 and $1511 \mathrm{~cm}^{-1}$ and can be attributed to the EA.

\subsubsection{FTIR Analysis Of The P(NIPAM) With Incorporated The EA And The A.}

\section{Vulgaris Extract}

After incorporation of the EA, or the A. vulgaris extract in the $\mathrm{p}$ (NIPAM), interaction by the type of the hydrogen bond between the phenolic -OH groups of EA with the oxygen in the $\mathrm{C}=\mathrm{O}$ and $\mathrm{CO}$ groups of $\mathrm{p}(\mathrm{NIPAM})$ side chains are expected. Also, the $\mathrm{C}=\mathrm{O}$ groups of EA can form hydrogen bonds with the NH group in the side chains of $\mathrm{p}$ (NIPAM). The FTIR spectrum of the synthesized p(NIPAM) with incorporated EA standard, or $A$. vulgaris extract (Figure 1) had the band $\delta(\mathrm{OH})$ at $1461 \mathrm{~cm}^{-1}$ which was shifted for 10 units to the higher wavenumbers in comparison to the spectrum of EA and extracts. The band of $v(\mathrm{NH})$ was shifted for 14 and 24 units toward higher wavenumbers (3303 and $3313 \mathrm{~cm}^{-1}$ ) in the spectrum of $\mathrm{p}(\mathrm{NIPAM})$ with incorporated EA, or extract, respectively. FTIR spectrum of $\mathrm{p}(\mathrm{NIPAM})$ with EA has a shift of $\delta(\mathrm{NH})$ for 12 units toward lower wavenumbers $\left(1546 \mathrm{~cm}^{-1}\right)$ in compared with the FTIR spectrum of $\mathrm{p}$ (NIPAM). The aforementioned facts indicates that the shifts of phenolic $\mathrm{OH}$ groups from EA, or extract, as well as NH groups from homopolymer side chains were mostly included in the hydrogen bonds formation. 


\subsubsection{FTIR Analysis Of The P(NIPAM-Hpmet) With Loaded EA And The A. Vulgaris Extract}

The band of $v(\mathrm{OH})$ in the FTIR spectrum of a p(NIPAM-HPMet) with incorporated EA or extract (Figure 1) were shifted for 3 units toward lower wavenumbers and 7 units to higher wavenumbers, respectively, compared to the copolymer spectrum. Also, there was a movement of the bands from $\delta(\mathrm{OH})$ to higher wavenumbers for 3 unit compared to the copolymer spectrum $\left(1462 \mathrm{~cm}^{-1}\right)$ and 14 units compared to the spectrum of A. vulgaris extract, or EA. The bands of $v(\mathrm{NH})$ in the spectrum of copolymer with EA and extract were appeared at 3301 and $3395 \mathrm{~cm}^{-1}$, respectively, and they were shifted to 15 and 21 units toward lower wavenumbers, compared to their position in the copolymer. Also, band of $\delta(\mathrm{NH})$ in FTIR spectrum of copolymer with EA, or extract, at $1551 \mathrm{~cm}^{-1}$, were shifted for 3 units toward lower wavenumbers, compared to their position in the $\mathrm{p}$ (NIPAM-HPMet) spectrum. The bands of $v(\mathrm{C}=\mathrm{O})$ in the $\mathrm{p}$ (NIPAM-HPMet) with EA, or A. vulgaris extract, were occured at $1718 \mathrm{~cm}^{-1}$ and $1716 \mathrm{~cm}^{-1}$, respectively. They were shifted for 9 units to the lower wavenumbers compared to their position in the p(NIPAMHPMet) spectrum. The above analysis of the FTIR spectra indicated that, in a p(NIPAMHPMet) with EA, i.e. A. vulgaris extract, the hydrogen bonding interactions occurred over the respective groups.

\subsection{SEM Analysis}

The morphological appearance of the p(NIPAM) and the p(NIPAM-HPMet) xerogels were amorphous-crystalline (Figure $2 \mathrm{a}$ and $2 \mathrm{~b}$, respectively). Comparing the surface structure of the p(NIPAM-HPMet) with p(NIPAM), does not show significant differences 
in morphology, especially taking into consideration the lack of uniformity of shape and pore size. Within the hydrogels structure, free ends of molecule parts with bulky side groups and pores built an amorphous area. The surface morphology of p(NIPAM) and p(NIPAM-HPMet) were changed after loading EA into the hydrogels (Figure $2 \mathrm{c}$ and $2 \mathrm{~d}$, respectively).

\subsection{Swelling Properties Of Hydrogels}

\subsubsection{Equilibrium Hydrogel Swelling}

Equilibrium swelling of $\mathrm{p}(\mathrm{NIPAM})$ and $\mathrm{p}(\mathrm{NIPAM}-\mathrm{HPMet})$ hydrogels at $37^{\circ} \mathrm{C}$ and $\mathrm{pH}$

7.40, which simulate intestinal condition, was monitored for $24 \mathrm{~h}$ and obtained results are shown in Figure 3.

Synthesized p(NIPAM-HPMet) hydrogel reached a higher swelling degree than $\mathrm{p}(\mathrm{NIPAM})$ at $37^{\circ} \mathrm{C}$. The swelling degree was intensively increased from the starting moment to the first $4 \mathrm{~h}$. It was observed that p(NIPAM-HPMet) reached a swelling degree at 6.76 ( $1 \mathrm{~g}$ of a sample can absorb a $6.76 \mathrm{~g}$ of water). The $\mathrm{p}$ (NIPAM) achived a lower swelling degree than the p(NIPAM-HPMet) and $1 \mathrm{~g}$ of a sample absorbs only 2.42 $\mathrm{g}$ of water. The water transport into $\mathrm{p}(\mathrm{NIPAM})$ and $\mathrm{p}(\mathrm{NIPAM}-\mathrm{HPMet})$ hydrogels was analyzed based on the sorption kinetics nature of the initial swelling data fitted to the exponential Ficks equation (3):

$$
\frac{M_{t}}{M_{e}}=k t^{n}
$$

where $M_{t} / M_{e}$ is the fractional sorption, $M_{\mathrm{t}}$ and $M_{\mathrm{e}}$ are the amounts of the absorbed solvent at time $t$ and equilibrium, respectively; $k$ is a kinetic constant incorporating characteristic 
of the network structure, $n$ is the diffusion exponent [10]. Ficks equation is only valid for the first $60 \%$ of the fractional uptake. The logarithmic form of Ficks equation was used to determine the values of $n$ and $k$, from slope and intercept the plots of $\ln \left(M_{t} / M_{e}\right)$ versus In $t$ for hydrogels. If $n$ is less than 0.5 the swelling process is controlled by the Fickian diffusion mechanism, whereas $n$ varies between 0.5 and 1 indicates an anomalous nonFickian type diffusion. The values of $n$ greater than 1 are described as Case III. The diffusion coefficient $D$, were calculated from the equation (4):

$\frac{M_{t}}{M_{e}}=\left(\frac{4}{\pi^{0,5}}\right)\left(\frac{D t}{l^{2}}\right)^{0,5}$

where $l$ is the thickness of the dried sample. The values for equilibrium swelling degree and kintetic parameters for the linear dependence of $\ln (\mathrm{Mt} / \mathrm{Me})$ on $\ln t$ of synthetised hydrogels at $37^{\circ} \mathrm{C}$ were presented in Table 1.

The calculated values for diffusion exponents, $n$, increased from 0,831 to 0,884 , so $\mathrm{p}$ (NIPAM-HPMet) and $\mathrm{p}($ NIPAM) were classified as hydrogels with anomalous transport behavior i.e. non-Fickian diffusion, which is intermediate between Fickian and Case II $(n=1)$. Their swelling process was controlled by the solvent diffusion and the relaxation of polymer chains.

\subsubsection{Thermosensitivity Of Synthesized Hydrogels}

Thermosensitivity of $\mathrm{p}$ (NIPAM) and $\mathrm{p}$ (NIPAM-HPMet) by swelling degree changing in dependence of temperature was studied and these results were shown in Figure 4. p(NIPAM-HPMet) has reached a greater value of swelling degree compared to the 
p(NIPAM) in distilled water. This increase of hydrophilicity can be explained by the lower crosslinkers content and addition of HPMet into the p(NIPAM) network. An important "intelligent" reaction was observed in adjusting the hydrogels swelling degree with a temperature change. $\mathrm{p}(\mathrm{NIPAM})$ has a LCST at $32^{\circ} \mathrm{C}$ and show a less expressive phase transition, while $\mathrm{p}$ (NIPAM-HPMet) has a phase transition detected at $34^{\circ} \mathrm{C}$ and expressed better thermosensitivity $[48,49]$ close to the human body temperature. This is important for the hydrogel application for modified release of drugs.

\subsection{Identification Of EA From A. Vulgaris Extract}

In order to identify the presence of EA in the methanol extract of UHPLC-DAD-HESIMS/MS method was used. Before analyzing of extract, EA standard was also subjected to LC-MS analyze. EA was identified at retention time of 7.01 min (Figure 5a) and mass peak at $m / z$ 337.51. After MS fragmentation two ion fragments at $m / z 301.22$ and 257.01 were present there (Figure 5b).

Ion fragment at $m / z 301.22$ represent a molecular ion of EA and ion fragment at $m / z$ 257.01 is characteristic ion fragment of EA [50]. Based on this it can be concluded that identified compound at 7.01 min with mass at $\mathrm{m} / \mathrm{z} 337.51$ represent ellagic acid with two added molecules of water. After that, A. vulgaris extract was subjected to UHPLC-DADHESI-MS/MS analysis and obtained result was present at Figure 5c. By looking at LCMS chromatogram of A. vulgaris extract it can be noted the presence of one peak at 7.07 min. Based on retention time, mass peak at $m / z 337.53$ and ion fragments at $m / z 301.21$ and 257.02, it can be concluded that this peak represent EA. In addition, results from LC- 
MS analysis were shown that extraction of $A$. vulgaris herb was a pretty selective for EA. In other words, results from LC-MS analysis showed that the content of other compounds were under the limit detection. This result gives a good basis for tracking of kinetics release of EA which was extracted from A. vulgaris. Determined EA content in $A$. vulgaris extract was $41 \mathrm{mg} \mathrm{g}^{-1}$ of dry extract, based on calibration curve.

\subsection{Dpph Assay}

The radical scavenging activity of EA standard and A. vulgaris extract were determined using DPPH assay and compared with the activity of synthetic antioxidant butylated hydroxytoluene (BHT). The functional dependency between the inhibition of 2,2diphenyl-1-picrylhydrazyl (DPPH) radicals and the concentrations of the investigated samples was presented in Figure 6. Increasing the EA concentration leads to an increase in inhibition of DPPH radicals. Maximum value of inhibition of DPPH radicals $(86.85 \%)$ was achieved at the EA concentration of $6.25 \mu \mathrm{gcm}^{-3}$. Unlike the EA standard which shows satisfactory antioxidant activity at the lower concentrations of solutions (0.2-100 $\mu \mathrm{gcm}^{-3}$ ), the A. vulgaris extract and BHT shows the same activity at the higher concentrations $\left(0.2-1000 \mu \mathrm{gcm}^{-3}\right)$ (Figure 6).

The $\mathrm{IC}_{50}$ values of EA standard, A. vulgaris extract and BHT were found to be 0.987 $\mu \mathrm{gcm}^{-3}, 23.12 \mu \mathrm{gcm}^{-3}$ and $36.6 \mu \mathrm{gcm}^{-3}$, respectively. After release of EA and A. vulgaris extract from $\mathrm{p}(\mathrm{NIPAM})$, the calculated $\mathrm{IC}_{50}$ values were 1.349 and $22.727 \mathrm{ggcm}^{-3}$, respectively. The calculated $\mathrm{IC}_{50}$ values for released EA and A. vulgaris extract from p(NIPAM-HPMet) were 1.968 and $23.218 \mu \mathrm{gcm}^{-3}$, respectively. The $\mathrm{IC}_{50}$ presents the 
concentration of investigated solution that is necessary to reduce the initial concentration of DPPH radicals to $50 \%$. Based on the obtained results of $\mathrm{IC}_{50}$, it can be concluded that the EA standard has better free DPPH radical scavenging activity in compared with the $A$. vulgaris extract and $\mathrm{BHT}$. The analysis of $\mathrm{IC}_{50}$ values for released $\mathrm{EA}$ and A. vulgaris extract from $\mathrm{p}(\mathrm{NIPAM})$ and $\mathrm{p}$ (NIPAM-HPMet) indicated the satisfactory antioxidant properties.

\subsection{The Total Flavonoids Content}

In order to determine the total flavonoids content in A. vulgaris extract, the calibration curve for rutin was construct. Linear dependency of the calibration curve, equation (5),

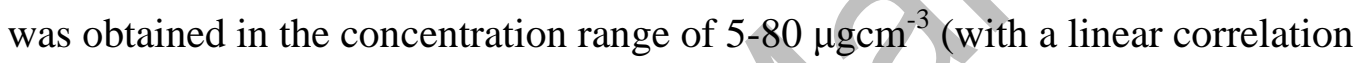
coefficient of 0.9978).

$$
A_{415}=0.0018 \cdot c_{\text {rutin }}+0.0652
$$

The calculated coefficient of determination $\mathrm{R}^{2}=0.9956$ indicates a well-fitting model, i.e. that $99.56 \%$ of absorbance variation can be explained by the proposed model. This claim was confirmed based on obtained results for analysis of variance (ANOVA), where F-value model of 915.63 was greater than the critical $F_{(0,05,1,4)}$ value of 7.71 . The determined total flavonoids content was found to be $0.303 \mathrm{~g}$ per $\mathrm{g}$ of dried extract. The high total flavonoids content was probably the reason of high antioxidant activity of the A. vulgaris extract.

\subsection{Incorporation Of EA In Hydrogels}


The content of EA in hydrogels $\mathrm{p}$ (NIPAM) and p(NIPAM-HPMet) was determined by measuring the samples mass before and after swelling in solutions of EA standard and $A$. vulgaris extract. In addition, the content of ellagic acid in the residual solutions was also confirmed by UHPLC-DAD-HESI-MS/MS method. The results showed a good correlation between the two methods of content analysis. The efficiency of incorporation, $\eta$, of EA into hydrogel was calculated by equation (6):

$\eta(\%)=\frac{L_{g}}{L_{u}} \times 100$

where $L_{\mathrm{g}}$ is mass of incorporated EA into hydrogel $\left(\mathrm{mgg}_{\mathrm{xerogel}}{ }^{-1}\right)$ and $L_{\mathrm{u}}$ is an initial mass of EA incorporated into the solution for hydrogel swelling $\left(\operatorname{mgg}_{\text {xerogel }}{ }^{-1}\right)$. The obtained values of incorporated EA into p(NIPAM) and p(NIPAM-HPMet) hydrogels were shown in the Table 2.

Based on the obtained results (Table 2), the highest incorporation efficiency was achieved with the EA standard (76.072\%) in p(NIPAM-HPMet). Also, the higher incorporation efficiency of $A$. vulgaris extract in p(NIPAM-HPMet) was achieved. p(NIPAM) showed satisfactory incorporation efficiency of EA standard and A. vulgaris extract, but less than p(NIPAM-HPMet) and achieved amounts were $64.264 \%$ and $62.478 \%$, respectively. The results of this analysis show better incorporation of EA in the p(NIPAM-HPMet), which is in accordance with the swelling degree of the synthesized hydrogels.

\subsection{Testing EA Release From Synthesized Hydrogels}


A standard solution of EA in methanol in the concentration range $0.001-0.1 \mathrm{mgcm}^{-3}$ was prepared. The calibration curve corresponds to linear equation (7) with a linear correlation coefficient of 0,9840 :

$A=110.1539+368209.5490 \cdot c$

where $A$ denotes the peak area (mAUs), and $c$ is the EA content $\left(\mathrm{mgcm}^{-3}\right)$. The results of released EA from the $\mathrm{p}$ (NIPAM-HPMet) and $\mathrm{p}$ (NIPAM) hydrogels at $37^{\circ} \mathrm{C}$ were shown in the Figure 7.

The p(NIPAM-HPMet) showed the highest released EA content $\left(22,701 \mathrm{mgg}_{\text {xerogel }}{ }^{-1}\right.$, which was $98.87 \%$ compared to the incorporated amount in hydrogel) at $37^{\circ} \mathrm{C}$. The hydrogels were contracted in body temperature (which was above the LCST) due to phase transition, intermolecular hydrogen bonds between the hydrogel and EA were broken and EA was released from the hydrogel. The kinetic parameters ( $n, \mathrm{k}$ and D) of the EA release mechanism from hydrogels were assessed by fitting experimental release data to Fick's equation (3) and presented in Table 2. Based on the calculated EA release kinetic parameters, p(NIPAM) was classified as hydrogel with non-Fickian diffusion, i.e. with anomalous transport behavior, while p(NIPAM-HPMet) was classified as Case III, i.e. time-independent kinetics at $37^{\circ} \mathrm{C}$.

\section{CONCLUSION}

FTIR analysis of the spectra of the monomer NIPAM, the synthesized p(NIPAM) and p(NIPAM-HPMet) confirm the successful polymerization reaction through the double bonds from the vinyl groups of monomers and crosslinker. The synthesized xerogels 
$\mathrm{p}($ NIPAM) and p(NIPAM-HPMet) were amorphous-crystalline. Better thermal sensitivity was achived by $\mathrm{p}(\mathrm{NIPAM}-\mathrm{HPMet}$, while $\mathrm{p}(\mathrm{NIPAM})$ shows less pronounced phase transition. The $\mathrm{p}$ (NIPAM-HPMet) reached a higher swelling degree compared to the $\mathrm{p}$ (NIPAM) and they were classified as hydrogels with non-Fickian diffusion at $37^{\circ} \mathrm{C}$.

The shifts of maximum absorption bands in FTIR spectra of $\mathrm{p}$ (NIPAM) and $\mathrm{p}$ (NIPAMHPMet) with included EA indicating the formation of intermolecular hydrogen bonds between the chains of the EA and hyddrogels. EA standard in a lower solution concentration $\left(0.2 \mathrm{gcm}^{-3}-0.1 \mathrm{mgcm}^{-3}\right)$ exhibiting satisfactory antioxidant activity, while a solution of $A$. vulgaris extract showed the same at higher concentrations. The $\mathrm{IC}_{50}$ values of EA standard, A. vulgaris extract and BHT were $0.987 \mu \mathrm{gcm}^{-3}, 23.12 \mu \mathrm{gcm}^{-3}$ and 36.6 $\mu \mathrm{gcm}^{-3}$, respectively. The total flavonoids content was $0.303 \mathrm{~g}$ in $1 \mathrm{~g}$ of dry extract. Copolymer $\mathrm{p}$ (NIPAM-HPMet) at $37^{\circ} \mathrm{C}$ showed better incorporation efficiency with the EA standard (76.07\%) and releasing of EA standard and A. vulgaris extract (98.87 and $96.45 \%$, respectively, compared to the incorporated EA amount), than p(NIPAM). The EA release process at $37^{\circ} \mathrm{C}$ was controlled by the non-Fickian diffusion from $\mathrm{p}$ (NIPAM) and the time-independent kinetics from p(NIPAM-HPMet).

\section{ACKNOWLEDGEMENTS}

This work was a part of the research done within the project TR-34012. The authors would like to thank to the Ministry of Education, Science and Technological Development, Republic of Serbia. 


\section{REFERENCES}

1. Peppas, N. A.; Bures, P.; Leobandung, W.; Ichikawa, H. Eur. J. Pharm. Biopharm. 2000, 50, 27-46.

2. Qiu, Y.; Park, K. Adv. Drug Deliver. Rev. 2001, 53, 321-339.

3. Zhang, X.-Z.; Yang, Y.-Y.; Wang, F.-J.; Chung, T.-S. Langmuir. 2002, 18, 2013-2018.

4. Andersson, M., Axelsson, A.; Zacchi, G. J. Controll. Release, 1998, 50, 273-281.

5. Schilli, C. M.; Zhang, M.; Rizzardo, E. S.; Thang (Bill), H. Y.; Chong, K.; Edwards,

K.; Karlsson, G. A.; Müller, H. E. Macromolecules. 2004, 37, 7861-7866.

6. Grassi, G.; Farra, R.; Caliceti, P.; Guarnieri, G.; Salmaso, S.; Carenza, M.; Grassi, M. American J. Drug Delivery.1922, 3, 239-251.

7. Coughlan, D. C.; Quilty, F. P.; Corrigan, O. I. J. Controll. Release, 2004. 98, 97-114.

8. Gan, T.; Zhang, Y.; Guan, Y. Biomacromolecules, 2009, 10, 1410-1415.

9. Bajpai, A. K.; Shukla, S. K.; Bhanu, S.; Kankane, S. Prog. Polim. Sci. 2008, 33, 10881118.

10. Ilić-Stojanović, S.; Nikolić, Lj.; Nikolić, V.; Ristić, I.; Budinski-Simendić, J.; Kapor, A.; Nikolić, G. Polymer International, 2014, 63, 973-981.

11. Ilić-Stojanović, S.; Nikolić, Lj.; Nikolić, V.; Milić, J.; Petrović, S. D.; Nikolić, G.; Kapor, A. Hem. ind. 2012, 66(6), 831-839.

12. Ilić-Stojanović, S.; Nikolić, Lj.; Nikolić, V.; Milić, J.; Stamenković, J.; Nikolić, G.;

Petrović, S. D. Hem. ind. 2013, 67(6), 901-912.

13. Grasser, G. Synthetic Tannins, Project Gutenberg-tm, eBook, 2005.

14. Loarca-Pina, G.; Kuzmicky, P. A.; de Mejía, E. G.; Kado, N. Y.; Hsieh, D. P. H. Mutat. Res. Environ. Mutagen Relat. Subj. 1996, 360, 15-21. 
15. Narayanan, B. A.; Geoffroy, O.; Willingham, M. C.; Re, G. G.; Nixon, D. W. Cancer Lett.1999, 136, 215-221.

16. Seeram, N. P.; Adams, L. S.; Henning, S. M.; Niu, Y.; Zhang, Y.; Nair, M. G.; Heber, D. J. Nutr. Biochem.2005, 16, 360-367.

17. Mandal, S.; Stoner, G. Carcinogenesis. 1988, 9, 1313-1316.

18. Mandal, S.; Stoner, G. Carcinogenesis. 1990, 11, 55-61.

19. Rogerio, A.; Fontanari, P. C.; Borducchi, E.; Keller, A. C.; Russo, M.; Soares, E. G.;

Albuquerque, D. A. L.; Faccioli, H. Eur. J. Pharmacol. 2008. 580, 262-270.

20. Priyadarsini, K. I.; Khopde, S. M.; Kumar, S. S.; Mohan, H. J. Agric. Food Chem. 2002, 50, 2200-2205.

21. Khanduja, K. L.; Gandhi, R. K.; Pathania, V. N. Food Chem. Toxicol. 1999, 37, 313318.

22. Edderkaoui, M.; Odinokova, I.; Ohno, I.; Gukovsky, I.; Go, V. L. W.; Pandol, S. J.;

Gukovskaya, A. S. World J. Gastroenterol. 2008, 14, 3672-3680.

23. Umesalma, S.; Sudhandiran, G. Eur. J. Pharmacol. 2011, 660, 249-258.

24. Soh, P. N.; Witkowski, B.; Olagnier, D.; Nicolau, M. L.; Garcia-Alvarez, M. C.;

Berry, F.; Benoit-Vical, A. Agents Chemother. 2009, 53, 1100-1106.

25. Stamenković, V. Our innocuous herbs, Trend: Leskovac, Republic of Serbia, 2005.

(in Serbian).

26. Fraisse, D. A.; Carnat, A. P.; Carnat, J.; Lamaison, L. Ann. Pharm. Fr.1999, 57, 401405.

27. Lamaison, J. L.; Carnat, A.; C. Petitjean-Freytet, A.; Carnat, P. Ann. Pharm. Fr. 1991, 49, 186-189. 
28. Heikel, H. Contribution to the Study of Alchemilla vulgaris, D. Pharm. Thesis, Claude Bernard University, Lyon, 1995.

29. Jonadet, M.; Meunier, M. T.; Villie, F.; Bastide, J. P.; Lamaison, J. L. J. Pharmacol. 1986, $17,21-27$.

30. Filipek, J. Pharmazie. 1992, 47, 717-724.

31. Williams, C. A.; Grayer, R. J. Nat. Prod. Rep. 2004, 21, 539-573.

32. Aquino, R.; Morelli, S.; Tomaino, A.; Pellegrino, M.; Saija, A.; Grumetto, L.;

Pugliae, C.; Venturae, D.; Boninae, F. J. Ethnopharmacol. 2002, 79, 183-191.

33. Choi, C. W.; Kim, S. C.; Hwang, S. S.; Choi, B. K.; Ahn, H. J.; Lee, M. Y.; Park, S. H.; Kim, S. K. Plant Sci. 2002, 163, 1161-1168.

34. Sanchez-Moreno, C. Food Sci. Technol. Int. 2002, 8, 121-137.

35. Cvetkovic, Z.; Nikolic, V.; Savic, I.; Savic-Gajic, I.; Nikolic, Lj. Hem. Ind. 2015, 69, 679-687.

36. Quian, H.; Nihorimbere, V. J. Zhejiang University Sci. 2004, 5, 676-683.

37. Woisky, R. G.; Salatino, A. J. Apicult. Res. 1998, 37, 99-105.

38. Savić, I.; Nikolić, V.; Savić, I.; Nikolić, Lj.; Stanković, M.; Moder, K. Hem. Ind. 2012, 67, 249.

39.Chang, C. C.; Yang, M. H.; Wenm, H. M.; Chern, J. C. J. Food Drug Anal. 2002, 10, $178-182$.

40. Cheng, H. Shen,; L. C.; Wu, L.L.S. Macromolecules. 2006, 39, 2325-2329.

41. Rzaev, Z. M. O.; Dincer, S.; Piskin, E. Prog. Polym. Sci. 2007, 32, 534-595.

42. Hussein, M. Z.; Hasan, S. A. A.; Zainal, Z.; Hakim, M. N. Int. J. Nanomed. 2011, 6, 1373-1383. 
43. Cursino, A. C. T.; Gardolinski, J.; Wypych, F. J. Colloid. Interface Sci. 2010, 347, 49-55.

44. Hasegawa, M.; Terauchi, M.; Kikuchi, Y.; Nakao, A.; Okubo, J.; Yoshinaga, T.;

Hiratsuka, H.; Kobayashi, M.; Hoshi, T. Monatsheftefür Chemie/Chemical Monthly. 2003, 134, 811-821.

45. Nayeem, N.; Karvekar, M. D. Res. J. Pharm. Biol. Chem. Sci. 2010, 1, 221-225.

46. Bindra, R. S.; Satti, N. K.; Suri, O. P. Phytochemistry. 1988, 27, 2313-2315.

47. Kim, S.; Liu, Y.; Gaber, M. W.; Bumgardner, J. D.; Haggard, W. O.; Yang, Y. J. Biom. Mater. Res. B Appl. Biomater. 2009, 90, 145-155.

48. Nizam El-Din, H. M. J. Appl. Polym. Sci. 2011, 119, 577-585.

49. Cai, W. E.; Anderson, C.; Gupta, R. B. Ind. Eng. Chem. Res. 2001, 40, 2283-2288.

50. Mullen, W.; Yokota, T.; Lean, M. E.; Crozier, J. A. Phytochemistry. 2003, 64, 617641. 
Table 1. Equilibrium swelling ratio, $\alpha$, and kinetic parameters of water diffusion into $\mathrm{p}(\mathrm{NIPAM})$ and $\mathrm{p}\left(\right.$ NIPAM-HPMet) hydrogels at $37^{\circ} \mathrm{C}$

\begin{tabular}{|l|l|l|l|l|l|}
\hline Hydrogel sample & $\alpha\left(\mathrm{g} \mathrm{g}^{-1}\right)$ & $n$ & $\mathrm{k} \times 10^{3}\left(\mathrm{~min}^{-1 / 2}\right)$ & $R^{2}$ & $\mathrm{D}\left(\mathrm{cm}^{2} \mathrm{~min}^{-1}\right)$ \\
\hline $\mathrm{p}$ (NIPAM) & 2.42 & 0,884 & 0,624 & 0,981 & $5.198 \times 10^{-5}$ \\
\hline p(NIPAM-HPMet) & 6.76 & 0.831 & 1.065 & 0,975 & $1.209 \times 10^{-4}$ \\
\hline
\end{tabular}


Table 2. Mass of incorporated EA $\left(\mathrm{L}_{\mathrm{g}}\right)$, the efficiency of incorporation $(\eta)$ the amount and percent of released EA; the EA release kinetic parameters $(n, \mathrm{k}$ and $\mathrm{D})$ at $37^{\circ} \mathrm{C}$, from $\mathrm{p}($ NIPAM) and p(NIPAM-HPMet) hydrogels

\begin{tabular}{|l|l|l|l|l|}
\hline Sample & $\begin{array}{l}\text { p(NIPAM) } \\
\text { with EA }\end{array}$ & $\begin{array}{l}\text { p(NIPAM- } \\
\text { HPMet) with EA }\end{array}$ & $\begin{array}{l}\text { p(NIPAM) with } \\
\text { extract }\end{array}$ & $\begin{array}{l}\text { p(NIPAM-HPMet) } \\
\text { with extract }\end{array}$ \\
\hline Xerogel mass $(\mathrm{g})$ & 0.0495 & 0.0497 & 0.0482 & 0.0494 \\
\hline$L_{\mathrm{g}}\left(\mathrm{mg} \mathrm{g}_{\text {xerogel }}{ }^{-1}\right)$ & 19.474 & 22.959 & 19.443 & 21.399 \\
\hline$\eta(\%)$ & 64.264 & 76.072 & 62.478 & 70.476 \\
\hline Released EA (mg & 17.745 & 22.701 & 16.730 & 20.639 \\
\hline$\left.g_{\text {xerogel }}{ }^{-1}\right)$ & & & & \\
\hline Released EA $(\%)$ & 91.119 & 98.873 & 86.046 & 96.448 \\
\hline$N$ & 1,472 & 0,758 & 1,897 & 0,905 \\
\hline $\mathrm{k} \times 10^{3}\left(\mathrm{~min}^{-1 / 2}\right)$ & 0,763 & 2,555 & 0,101 & 1,177 \\
\hline$R^{2}$ & 0,995 & 0,998 & 0,993 & 0,996 \\
\hline $\mathrm{D} \times 10^{6}\left(\mathrm{~cm}^{2} \mathrm{~min}^{-1}\right)$ & 0,457 & 5,126 & 0,080 & 1,088 \\
\hline
\end{tabular}


Figure 1. FTIR spectra of EA standard, A. vulgaris extract, p(NIPAM), p(NIPAM) with EA standard, p(NIPAM) with A. vulgaris extract, p(NIPAM-HPMet), p(NIPAM-HPMet) with EA standard and p(NIPAM-HPMet) with A. vulgaris extract

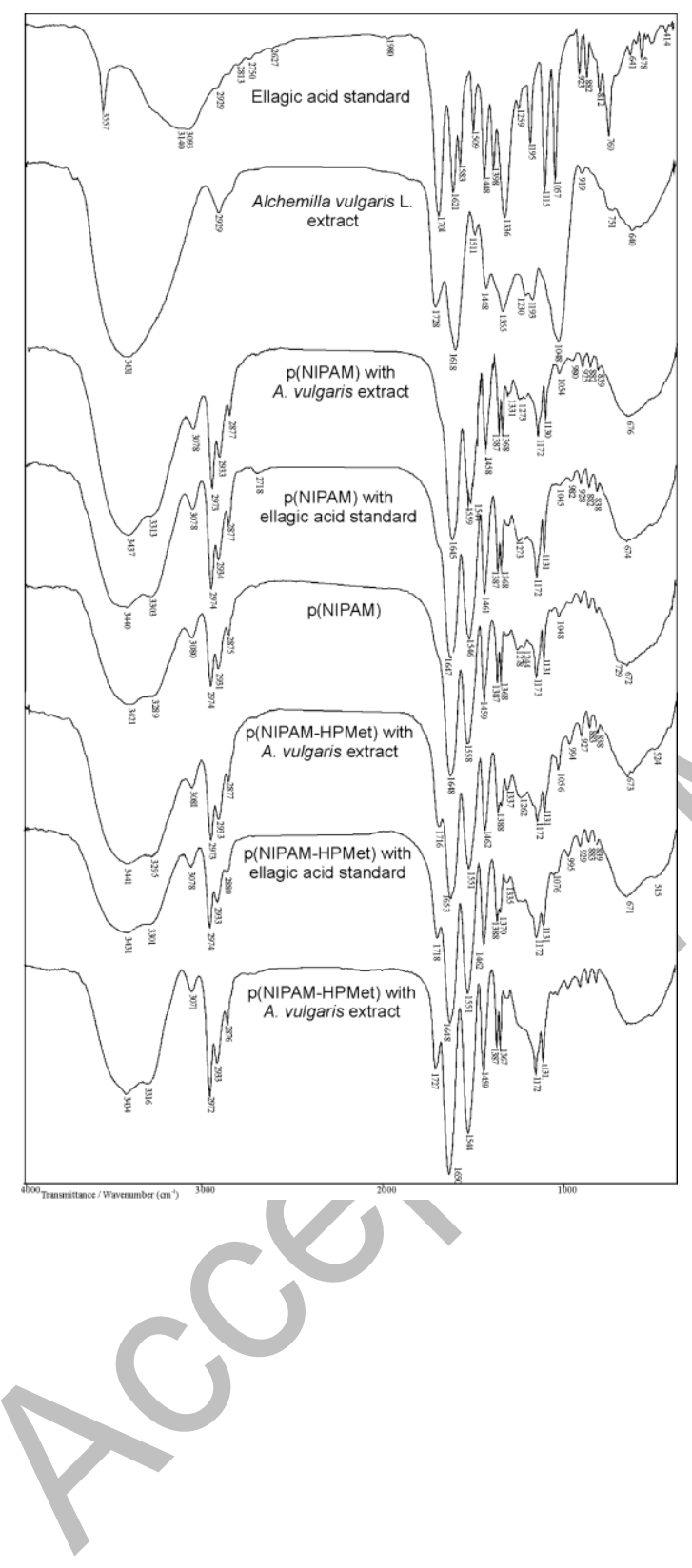


Figure 2. Scanning electron micrographs of xerogels: a) p(NIPAM), b) p(NIPAMHPMet), c) p(NIPAM) with loaded EA, d) p(NIPAM-HPMet) with loaded EA
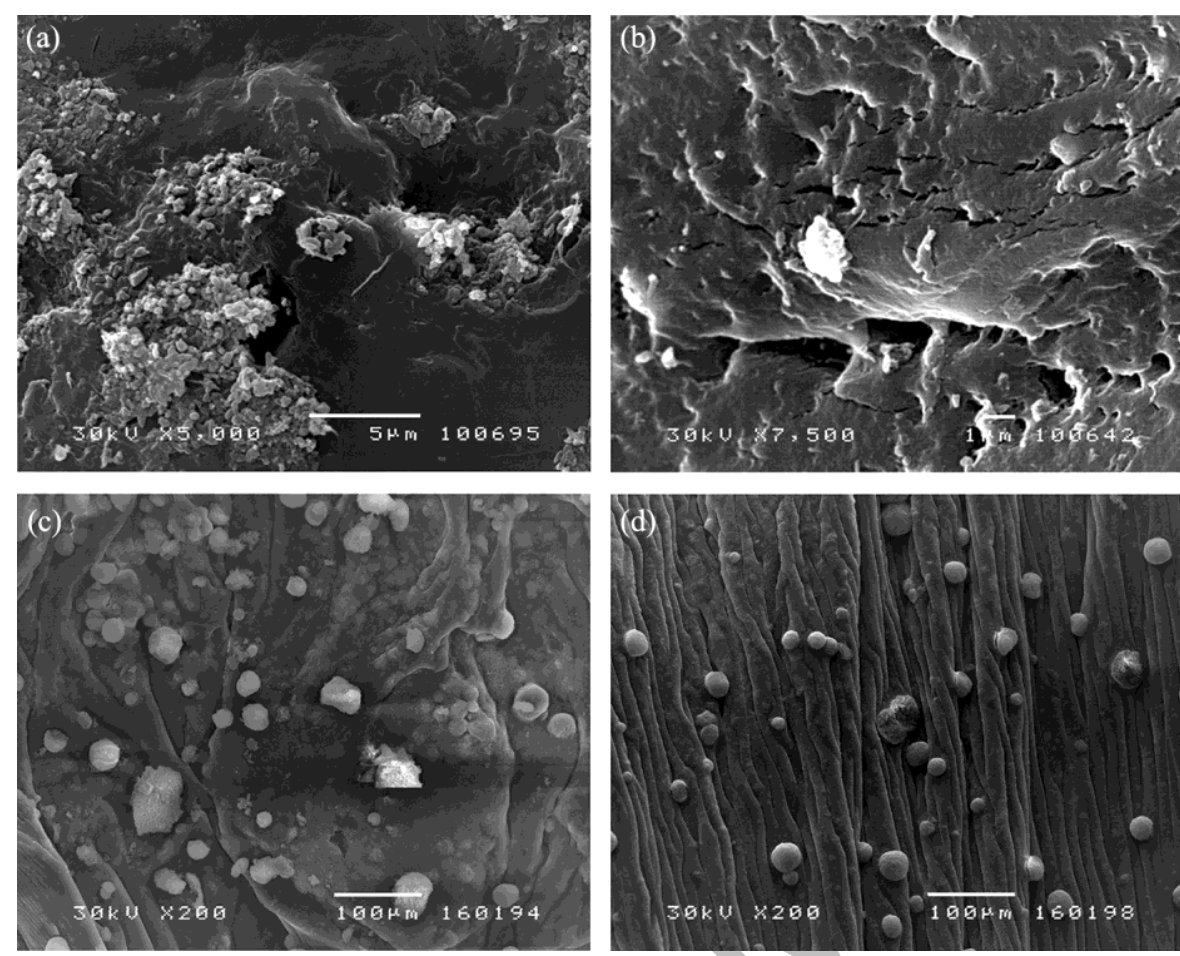
Figure 3. Equilibrium swelling of $\mathrm{p}(\mathrm{NIPAM})$ and $\mathrm{p}(\mathrm{NIPAM}-\mathrm{HPMet})$ depending on time at $37^{\circ} \mathrm{C}$

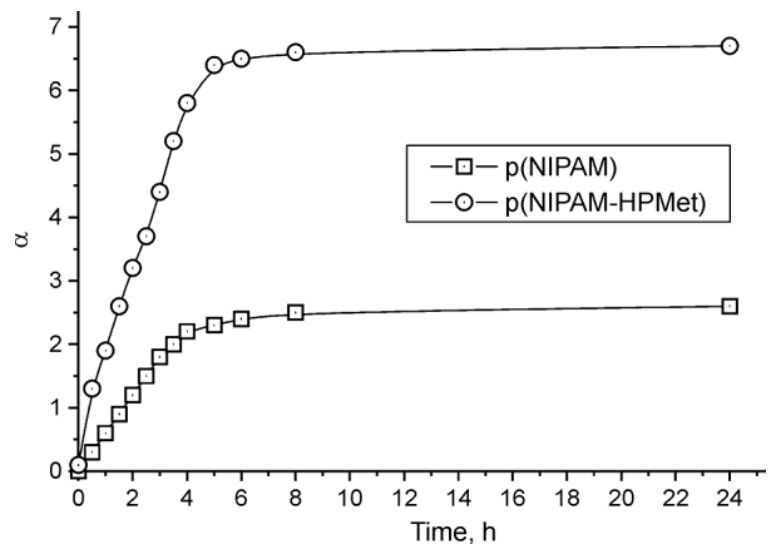


Figure 4. Change of the swelling degree for $\mathrm{p}(\mathrm{NIPAM})$ and $\mathrm{p}(\mathrm{NIPAM}-\mathrm{HPMet})$ hydrogels depending on the temperature

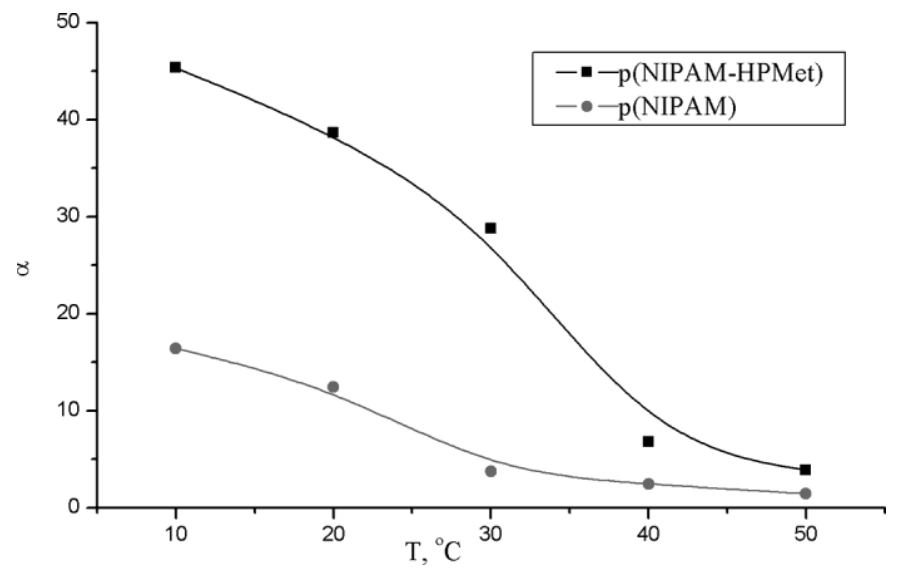


Figure 5. a) LC-MS chromatogram of EA standard $\left(t_{R}=7.1 \mathrm{~min}\right)$, b) MS fragmentation of EA, c) LC-MS chromatogram of A.vulgaris extract
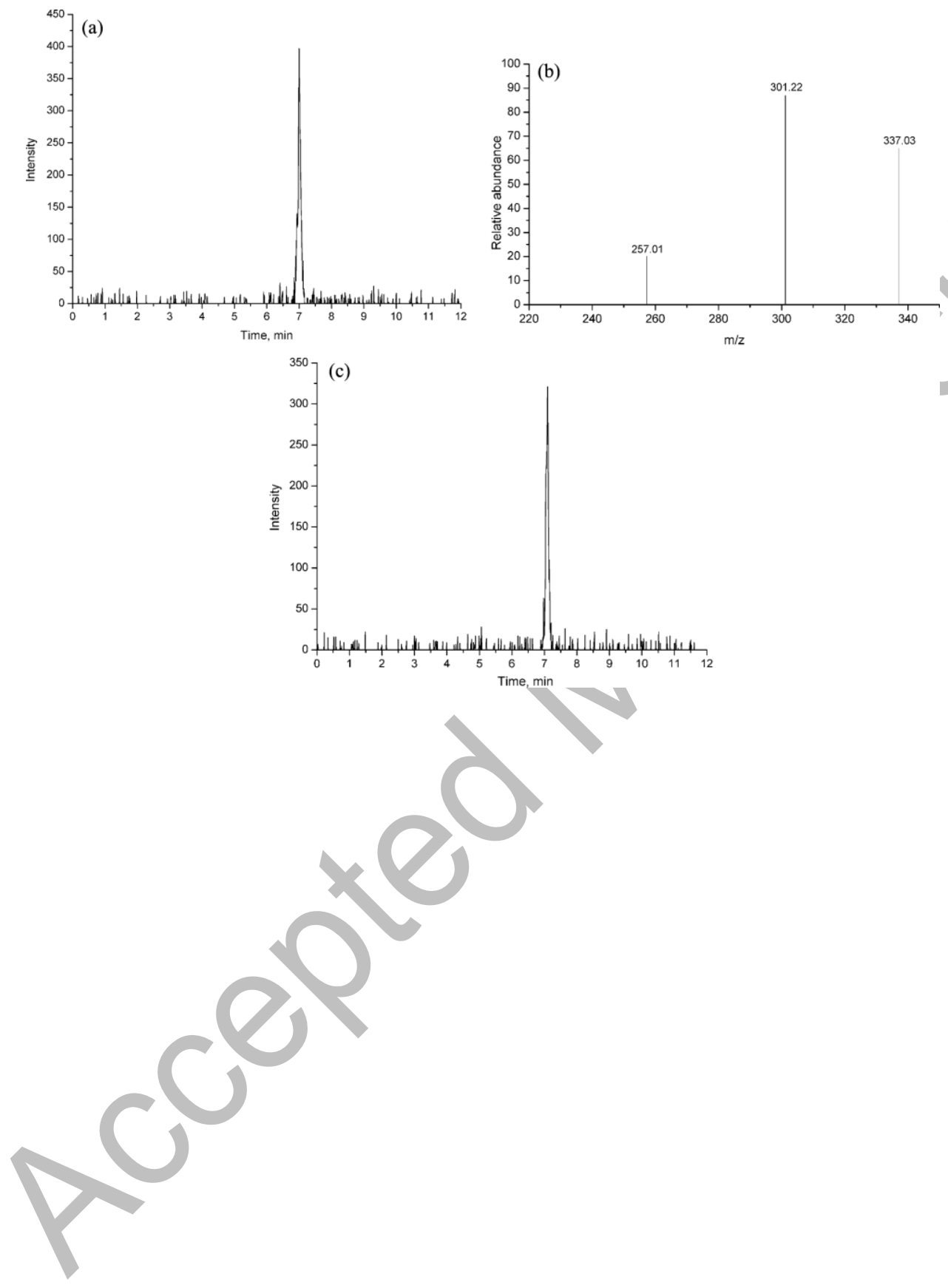
Figure 6. Antioxidant activity of EA and A. vulgaris extract before and after release from the $\mathrm{p}(\mathrm{NIPAM})$ and $\mathrm{p}(\mathrm{NIPAM}-\mathrm{HPMet})$ hydrogels

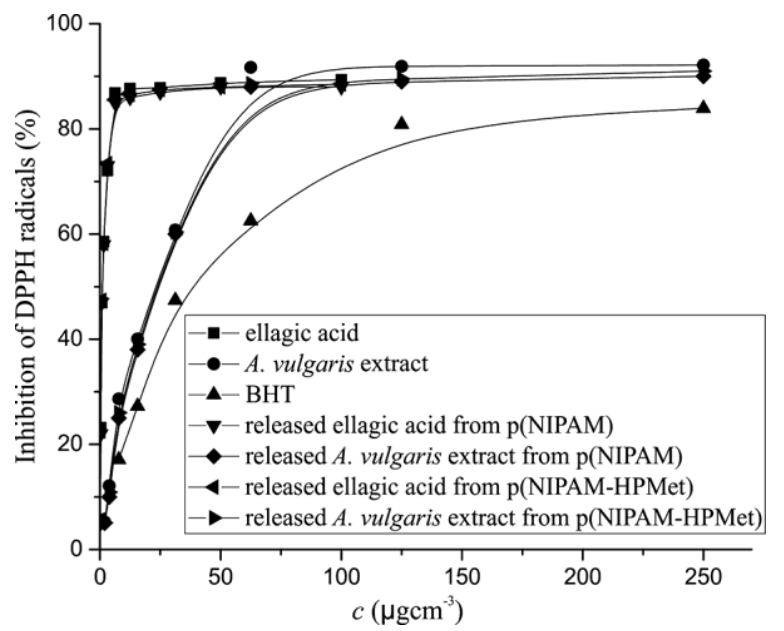


Figure 7. The released EA from $\mathrm{p}(\mathrm{NIPAM}-\mathrm{HPMet})$ and $\mathrm{p}(\mathrm{NIPAM})$ hydrogels at $37^{\circ} \mathrm{C}$

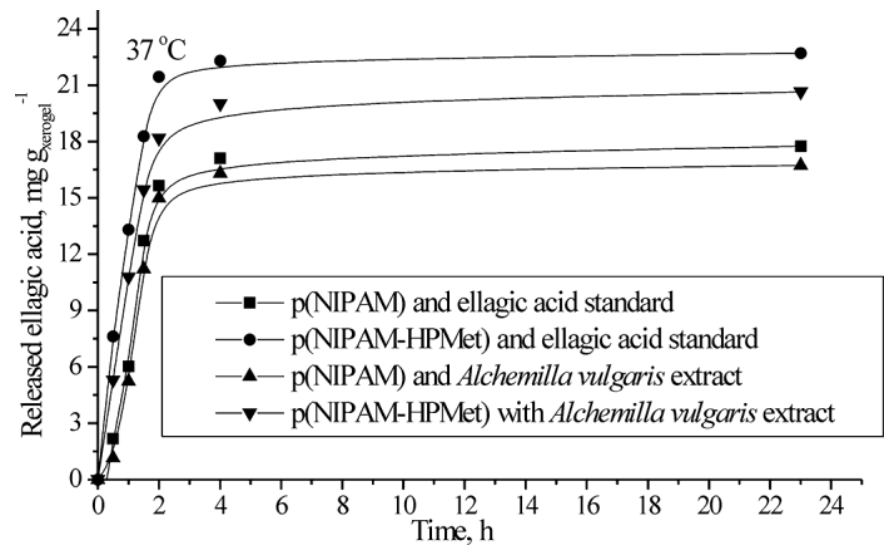

